\title{
Educação infantil na trilha das múltiplas inteligências: uma proposta de construção do conhecimento a partir de salas ambiente
}

Early childhood education on track of multiple intelligences: a proposal for knowledge of construction environment from rooms

Aloysia Pinz Klemann ${ }^{1}$

José Messildo Nunes²

\section{Resumo}

Este artigo tem como objetivo refletir sobre a dinâmica de funcionamento das Salas Ambientes de uma Eco-Escola à luz da Teoria das Inteligências Múltiplas trata-se de uma pesquisa qualitativa caracterizando-se como um estudo de caso etnográfico desenvolvida na Escola Municipal Alana de Souza Barboza, localizada em uma área da periferia de Belém-PA. A proposta é fundamentada pela Teoria das Inteligências Múltiplas de Howard Gardner. Na referida escola desenvolve-se um projeto intitulado Eco-Escola, esta proposta, privilegia a efetivação de projetos didáticos em Salas Ambientes, ressaltando sempre o enfoque ecológico. A Amazônia se habilita como um ambiente apropriado a este tipo de projeto, a valorização da cultura Amazônica também é focada por meio de projetos didáticos cujos temas são as lendas do folclore Amazônico. Essas lendas identificam as Salas Ambientes, fazendo com que as crianças se afeiçoem cada vez mais com a cultura, pois ela é a mola propulsora de todos os conhecimentos. Constatamos nessa pesquisa que as Salas Ambientes auxiliam na aprendizagem dos alunos, a dinâmica de rodízio entre as salas favorece a construção do saber.

Palavras chaves: inteligências múltiplas; salas ambientes; lendas amazônicas

\begin{abstract}
This article aims to reflect on the dynamics of operating of ambient classrooms an Eco-School on the Theory of Multiple Intelligences it is a qualitative research characterized as an ethnographic case study developed at the Municipal School Alana de Souza Barboza, located in an area of the outskirts of Belém-PA. Howard Gardner's Multiple Intelligences Theory supports the proposal. In the referred school a project called "Eco-Escola" is developed, this proposal favors the realization of didactic projects inside the ambient classrooms, always emphasizing an ecological approach. The Amazon qualifies as an appropriate environment for this type of project. The appreciation of Amazon's culture is also focused by the didactic projects that have Amazon's legends as their theme. These legends identify the ambient classrooms, causing children to identify with the culture themselves because culture is the mainspring of all knowledge. We noted in this research that the ambient classrooms assist in the students' learning process and that the dynamics of rotating between classrooms favors the construction of knowledge.
\end{abstract}

Keywords: multiple intelligences; ambient classrooms, amazon legends.

\footnotetext{
${ }^{1}$ Secretaria Municipal de Educação de Belém/PA | vappja@gmail.com

${ }^{2}$ Universidade Federal do Pará | messildo@ufpa.br
} 


\section{Introdução}

No processo educativo um dos pontos centrais que as instituições escolares devem focar é a capacidade em ampliar o olhar para a vida e o potencial crítico do discente. Tal conscientização deve ser desenvolvida desde os anos iniciais de escolaridade, por meio de diálogos e regras acordadas para que o aluno possa desenvolver hábitos que the possibilite tomar consciência de seu papel no processo de ensino e aprendizagem.

Temos consciência que a função da escola hoje é muito mais do que transmitir conteúdos sistematizados. Para isso, deve-se incluir a aquisição de hábitos e habilidades e a formação de atitudes investigativas frente ao próprio conhecimento, uma vez que o aluno deverá ser capaz de ampliá-lo e reconstruí-lo quando necessário, além de aplicá-lo em situações próprias do seu contexto de vida.

Nesse sentido, as instituições escolares devem tomar como base enfoques que favoreçam a apropriação dos conteúdos abordados com significado, e valorize regras de convivência e diálogo, tornando a escola um ambiente que possa favorecer a constituiçao de cidadãos conscientes de seus afazeres frente a problemas do dia a dia.

Se as relações humanas, embora complexas, são peças fundamentais na realização de mudanças em nível profissional e comportamental, não podemos ignorar a importância das relações estabelecidas entre os atores e a instituição em que estão inseridos. Elias (2000) destaca: "É por intermédio das modificações comportamentais da área afetiva que a escola pode contribuir para a fixação dos valores e dos ideais que a justificam como instituição social."

A aprendizagem no contexto escolar deve possibilitar ao discente: compartilhar, responder e comunicar-se com o professor e os outros estudantes com respeito recíproco. A afetividade que emerge das relações vividas no espaço escolar pode ser usada como uma estratégia educativa fundamental de ensino que valoriza o espírito criativo, crítico e cooperativo.

A experiência cooperativa em atividades diversificadas, como leitura, escrita, discussões e ações que enfoquem e valorizem a consciência ambiental, não só ajuda os alunos a apreenderem os conteúdos, mas também prepara o cidadão para resolverem problemas da vida diária - no trabalho em família, etc. - de forma coletiva e responsável.

Nessa perspectiva, a Eco-Escola Municipal de Educação Infantil Alana de Souza Barboza, situada no Conjunto Ariri Bolonha, mantida pela Secretaria Municipal de Educação e Cultura (SEMEC) da Prefeitura Municipal de Belém no Estado do Pará, busca formar cidadãos que apresentem visão ampla sobre os conhecimentos necessários para viver em sociedade, aguçando competências específicas afloradas em atividades diversificadas.

Tomando como referência a escola supracitada temos como objetivo neste artigo refletir sobre a dinâmica de funcionamento das Salas Ambientes dessa Eco-Escola à luz da Teoria das Inteligências Múltiplas.

Para alcançar nosso objetivo desenvolvemos uma pesquisa qualitativa compreendida como estudo de caso etnográfico, pois apresenta requisitos etnográficos tais como expressos neste texto, como também os requisitos do estudo de caso, "que seja um sistema bem definido, isto é, uma unidade com limites bem definidos, tal como uma pessoa, um programa, uma instituição ou um grupo social" (ANDRÉ, 2005, p. 31). Neste aspecto, entendemos que nossa pesquisa atende a estes requisitos, dessa forma pode ser entendida como um estudo de caso etnográfico. 
O estudo de caso etnográfico permite ao pesquisador um olhar profundo e também vasto, porém integrado na unidade complexa. O estudo de caso é "um trabalho de campo intenso e prolongado, o que requer tempo e recursos por parte do pesquisador" (ANDRÉ, 2005, p. 49). Porém, esta metodologia de pesquisa torna-se ideal quando o pesquisador tem como objetivo, estudar um caso particular considerando seu contexto e complexidade. Referente à escolha desta metodologia André (2005) sublinha:

Uma das vantagens do estudo de caso geralmente mencionado é a possibilidade de fornecer uma visão profunda e ao mesmo tempo ampla e integrada de uma unidade social complexa, composta de múltiplas variáveis. Para fazer este tipo de análise, no entanto, o pesquisador necessita investir muito tempo e recursos, seja no trabalho de campo, seja na interpretação e no relato de dados (ANDRÉ, 2005, p. 52).

Neste aspecto, destacamos a potencialidade do estudo de caso para retratar situações vivenciadas no cotidiano das práticas das Salas Ambientes da Eco-Escola em pauta, sem interferir na sua complexidade e dinâmica natural. Características como as mencionadas nesta parte do texto possibilitam enquadrar nossa pesquisa em um estudo de caso etnográfico nos termos propostos por André (2005).

No ambiente da pesquisa enfocaremos os princípios norteadores da proposta da EcoEscola, as competências e habilidades assumidas em termos de desenvolvimento do aluno; a organização ccurricular; eexplicitaremos, em termos gerais, as atividades didáticas destinadas à obtenção de experiências de formação do cidadão no ambiente escolar e comunitário e a avaliação como parte integrante do processo de formação.

\section{Fundamentos para ações teórico-práticas da escola}

A proposta de uma nova perspectiva para Educação Infantil pressupõe um processo de ensino e aprendizagem estruturado em uma metodologia diferenciada, que apoia as ações cotidianas direcionadas pedagogicamente para as crianças, observando seus interesses, suas necessidades e seus problemas, coerente com seu desenvolvimento cognitivo e em interação permanente com o ambiente natural e social. Pressupõe, também, uma prática que se constrói continuadamente pela análise de pontos importantes do processo educativo, revendo posturas, repensando ações, conceitos e teorias, os aspectos que alicerçam este fazer são:

- A aprendizagem significativa;

- A aprendizagem individual e coletiva;

- As múltiplas interações do aluno com o meio, com outros indivíduos e com o objeto do qual pretende se apropriar;

- A interação do aluno no seu processo de construção do conhecimento;

- O conteúdo sendo trabalhado além da forma conceitual, com possibilidades procedimentais e atitudinais;

- A pluralidade das inteligências e a consideração que o sujeito possui um espectro de competências a ser desenvolvido;

- A necessidade de atuar nas áreas lógico-matemáticas e linguísticas.

As práticas desenvolvidas nas Salas-Ambientes (SA) são norteadas por esses pontos. Trata-se de uma modalidade de organização metodológica fundamentada na Teoria das Inteligências Múltiplas, defendida por Howard Gardner, na qual a inteligência passa a ser 
encarada como um espectro de competência, definindo-a como a capacidade de resolver problemas ou de criar produtos que sejam valorizados dentro de um ou mais cenários culturais.

Nessa concepção a inteligência ganha uma dimensão abrangente, manifestada na forma de um conjunto de competências e habilidades associadas de diferentes formas (MACHADO, 1995; SMOLE, 2000).

Gardner (1994) afirma que o ser humano é dotado de múltiplas inteligências e que os cinco primeiros anos de vida são fundamentais para o seu desenvolvimento.

Todos os seres humanos são capazes de, pelo menos, sete diferentes modos de conhecer o mundo - modos que, em outros lugares eu defini como as sete inteligências humanas. De acordo com esta análise, todos nós estamos aptos a conhecer o mundo através da linguagem, da análise lógico-matemática, da representação espacial, pensamento musical, do uso do corpo para resolver problemas ou para fazer coisas, de uma compreensão de outros indivíduos e de uma compreensão de nós mesmo (GARDNER, 1994, p.14).

Bem mais que um método, a teoria das Inteligências Múltiplas representa uma nova e original concepção sobre o ser humano como afirma Antunes (1998a) o ser humano não é mais ou menos inteligente, mais ou menos capaz, na realidade é portador de expressivo elenco de inteligências diferenciadas, permitindo uma identificação de diferenças significativas entre sua capacidade de aprendizagem e de comunicação.

Uma escola que leve em consideração a teoria de Gardner deve ter como propósito desenvolver as inteligências e auxiliar as pessoas a atingir harmonia em seu espectro de competências (SMOLE, 1999, p. 19).

Tomando como referência as indicações da Teoria das Inteligências Múltiplas A EcoEscola Alana de Souza Barboza apresenta a organização dos espaços das SA na perpectiva de explorar as sete inteligências anunciadas por Gardner (1994).

As sete competências [...] relacionadas compõem um espectro onde todos os elementos componentes interagem, equilibrando-se ou reequilibrando-se em razão de deficiências específicas [...] A pressuposição implícita é a de que toda criança teria possibilidade de um desenvolvimento global de suas competências, podendo revelar-se especialmente "inteligentes" em uma ou mais áreas de interesse. À escola cabe estimular a emergência dessas áreas alimentando os interesses despertados, oferecendo canais adequados para sua manifestação e seu desenvolvimento. (MACHADO, 1995, p. 98).

Apesar das SA estarem organizadas de forma a dar ênfase a competências específicas levamos em conta as interações entre as competências.

As inteligências interagem e, apesar da distinção que Gardner estabelece entre elas, nada seria feito, ou nenhum problema se resolveria, se as pretendidas distinções e a independência significassem que as inteligências não pudessem trabalhar juntas (SMOLE, 2000, p.27).

Para a autora suprareferenciada um problema linguístico que não abranja as dimensões linguística e espacial, pode apresentar-se insolúvel. Mais que isso, ele afirma que 
cada papel cultural que o indivíduo assume na sociedade, seja qual for o grau de sofisticação, requer uma combinação de inteligências.

Assim, os espaços das SA são pensadas sob a perspectiva de não haver uma competência mais importante que a outra, já que, na sua caracterização, todas tem igual importância.

\title{
O Sistema de Salas Ambientes (SA)
}

A característica principal do sistema de SA é variedade e a natureza das atividades, uma vez que nelas se oferecem oportunidades diversificadas e liberdade, na escolha e no manuseio de materiais. Além de proporcionar a ampliação dos espaços de trabalho e circulação das crianças, apresenta a potencialidade de favorecer boas relações interpessoais com seus colegas e professores.

As SA são concebidas como espaços físico-pedagógicos, organizados com vistas a estimular todas as áreas do conhecimento, e de modo a contemplar a criança como um todo. Suas ações pressupõem uma organização por meio de rodízios.

O processo educativo efetivado nas SA desafia as crianças a relacionarem os saberes entre si, estimula a descoberta, motivando-as a conhecer sua realidade enquanto sujeito social. De acordo com Demo (1992, p. 82).

\begin{abstract}
Talvez se possa estranhar, mas isso começa no pré-escolar, compreendido de 0 a 6 anos de idade, portanto mais do que ninguém a criança vindo ao mundo coloca-se em estado estrutural de descoberta e criação. Tudo é novo, mesmo chocante, e exige dela constante aprender, principalmente aprender a aprender. Podemos realizar em torno dela rígido controle domesticador, com vistas a que reproduza fielmente os parâmetros vigentes da sociedade, da família, mas podemos também motivar processo emancipatório radical, a partir do qual se elabora nova oportunidade, novo sujeito social, nova cidadania de base. O Pré-escolar se destina a isso, se compreendermos como lugar estratégico da conquista, da autodeterminação, do jogo e da educação como tal. Aí já temos em pleno sentido educação política, processo emancipatório, dos quais faz parte a pesquisa.
\end{abstract}

O processo de pesquisa é estimulado no sistema de SA, ou seja, desenvolvem-se atividades que levam os discentes intuir, conjecturar, experimentar, provar e avaliar, além de reforçar atitudes de autonomia e cooperação. Tal perspectiva enriquece o conhecimento suscitado em sala de aula, esta multiplicidade de inteligências que são afloradas a cada rodízio empreendido potencializa aprendizagem contextualizada e com significado.

\section{A prática das inteligências múltiplas do dia a dia da escola}

\section{Organização do espaço}

A Educação Infantil possui características muito particulares no que se refere a organização dos ambientes: precisa de espaços amplos, diferenciados, de fácil acesso, identificados tanto por suas funções quanto pelas atividades que se realizam nos mesmos.

$\mathrm{Na}$ Eco-Escola Alana este detalhe foi cuidadosamente planejado por meio das SA todas as salas num total de sete são identificadas de acordo com as categorias elencadas na 
proposta da Teoria das Inteligências Múltiplas. As SA são concebidas como espaços físicopedagógicos organizados com vistas a estimular várias áreas do conhecimento, de modo a colocar as crianças frente a atividades que possibilitem ao máximo a exploração das inteligências anunciadas por Gardner (1995). A disposição das salas conforme as categorias podem ser observadas no Quadro 1.

Quadro 1: Salas Ambientes naEco-escola Alana de Souza Barboza

\begin{tabular}{|c|c|c|}
\hline Identificação da Sala & Inteligência - Habilidade & Linha de estimulação \\
\hline $\begin{array}{l}\text { Sala Ambiente de } \\
\text { Expressão e Produção }\end{array}$ & Inteligência Linguística & $\begin{array}{l}\text { Vocabulário, fluência verbal, gramática, } \\
\text { alfabetização, memória verbal. }\end{array}$ \\
\hline$\frac{\text { Sala Ambiente Natureza e }}{\underline{\text { Sociedade }}}$ & $\begin{array}{l}\text { Inteligência Naturalista e } \\
\text { Interpessoal }\end{array}$ & $\begin{array}{l}\text { Curiosidade, exploração, descoberta, } \\
\text { interação, aventuras, compreensão maior } \\
\text { do mundo natural e social, a partir de } \\
\text { observação, exploração e experimentação } \\
\text { do meio ambiental natural e nas suas } \\
\text { vivências sócio-culturais. }\end{array}$ \\
\hline$\underline{\text { Sala Ambiente de Jogos }}$ & $\begin{array}{l}\text { Inteligência Lógico- } \\
\text { Matemático }\end{array}$ & $\begin{array}{l}\text { Conceituação, sistema de numeração, } \\
\text { operação com conjuntos, instrumento de } \\
\text { medida, pensamento lógico. }\end{array}$ \\
\hline$\frac{\text { Sala Ambiente de Iniciação }}{\underline{\text { Musical }}}$ & $\begin{array}{l}\text { Inteligência Musical } \\
\text { e Cinestésico-Corporal }\end{array}$ & $\begin{array}{l}\text { Percepção auditiva, discriminação de } \\
\text { ruídos, compreensão de sons, } \\
\text { discriminação de sons, estrutura rítmica. } \\
\text { Motricidade e coordenação manual, } \\
\text { coordenação viso-motor e tátil, percepção } \\
\text { de formas, percepção de pesos e } \\
\text { tamanhos, paladar e audição. }\end{array}$ \\
\hline$\frac{\text { Sala Ambiente de }}{\underline{\text { Brinquedos }}}$ & $\begin{array}{l}\text { Inteligência Espacial /Pessoal e } \\
\text { Cinestésico Corporal }\end{array}$ & $\begin{array}{l}\begin{array}{l}\text { Lateralidade, orientação } \\
\text { orientação temporal, } \\
\text { alfabetizaçãão cartogradade, }\end{array} \\
\text { Motricidade e coordenação manual, } \\
\text { coordenação viso-motor e tátil, percepção } \\
\text { de formas, percepção de pesos e } \\
\text { tamanhos, paladar e audição. }\end{array}$ \\
\hline$\frac{\text { Sala Ambiente de Artes e }}{\text { Movimento }}$ & Inteligência Pitórica & $\begin{array}{l}\text { Reconhecimento de objetos, cores, formas } \\
\text { e tamanhos, percepção de fundo, viso- } \\
\text { motor. }\end{array}$ \\
\hline$\underline{\text { Sala de Multimeios }}$ & $\begin{array}{l}\text { Inteligência Pessoal e } \\
\text { Interpessoal. }\end{array}$ & $\begin{array}{l}\text { Percepção corporal, auto conhecimento e } \\
\text { relacionamento social, administração das } \\
\text { emoções, ética e empatia-automotivação } \\
\text { e comunicação interpessoal. }\end{array}$ \\
\hline
\end{tabular}

A utilização dessas salas no dia a dia pressupõe uma organização por meio de rodízio, mas conservando a divisão (por turmas), dos grupos de crianças segundo a idade, sob a coordenação de uma professora de referência para cada uma das salas.

Os diferentes tipos de ambientes e a dinâmica proposta para trabalhar as Inteligências Múltiplas requerem, em primeiro lugar, a organização de um cronograma de uso diário (rotatividade) para que cada turma troque de ambiente duas vezes ao dia, sempre com seu professor de referência.

- Cada professor atende a um nível de ensino de acordo com a faixa etária das crianças - 4 e 5 anos.

- As turmas são identificadas com personagens do Folclore Amazônico, pelo fato das Eco-Escolas terem seu foco na Amazônia, com ênfase na literatura infantil ressaltando as lendas, os mitos. Daí a nominação das turmas: 
No 1 - "MatintaPerera"- manhã e tarde - Faixa etária 4 anos.

No 2 - "Iara (Mãe D’água)"- manhã e tarde - Faixa etária 4 anos.

No 3 - "Boto" - manhã e tarde - faixa etária 4 anos.

No 4 - "Cobra Grande"- manhã faixa etária 4 anos / tarde faixa etária 5 anos

No 5 - "Uirapuru" - manhã e tarde - Faixa etária 5 anos.

No 6 - "Vitória Régia"- manhã e tarde - Faixa etária 5 anos .

No 7 - "Curupira"- manhã e tarde - Faixa etária 5 anos.

A denominação das turmas, por meio de personagens lendários, instiga a imaginação da criança e propicia não só a inserção no mundo letrado com ênfase na Amazônia em todos os seus aspectos (sociais, culturais, físicos, etc.), como também, dá suporte ao desenvolvimento dos Projetos Didáticos trabalhados em cada período.

\section{Desenvolvimento dos trabalhos nas Salas Ambientes}

Descreveremos algumas atividades desenvolvidas nas SA, nosso objetivo é apresentar a dinâmica de funcionamento das SA não sendo necessário discutir atividades desenvolvidas em todos os ambientes, assim elegemos quatro desses ambientes que achamos suficientes para apresentar essa dinâmica.

A Literatura é um elemento importante na rotina diária da escola e na exploração da inteligência linguística. Além de representar um estímulo forte à aprendizagem da leitura, favorece a criação de textos a contação de histórias, assim como pode propiciar novas e diversificadas vivências afetivo-emocionais, reorganizando percepções do mundo (ANTUNES, 2001) (Figuras1a e 1b).

Segundo Campos e Santos (2009, p. 110) é necessário que as escolas explorem as Inteligências Múltiplas de seus alunos, nesse sentido as instituições devem.

[...] proporcionar aos alunos um ambiente rico, valendo-se de uma tipologia variada de textos literários ou informativos, cultivando um novo público leitor capaz de compreender a sociedade em que vive e de transformá-la. De igual modo, o professor deve procurar criar em sua sala de aula um circuito de leitura: ler, contar histórias, estimular a troca de livros, reservar um tempo para ler em classe, abrir espaço para a escolha, pelo aluno, do que ele quer ler, propor textos correlacionados aos interesses do grupo e, enfim, criar ofertas múltiplas e instigantes, proporcionando, desse modo, uma imersão no mundo da leitura ao oferecer condições para que ela se torne, efetivamente, uma prática interdisciplinar e intertextual. 


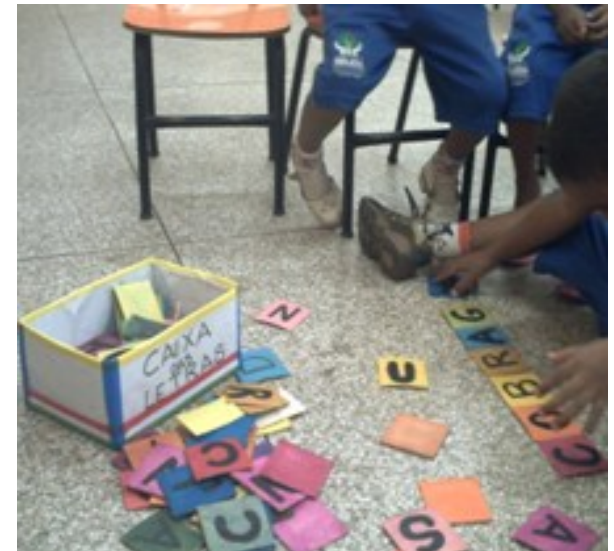

Figura 1a: Crianças descobrindo palavras.

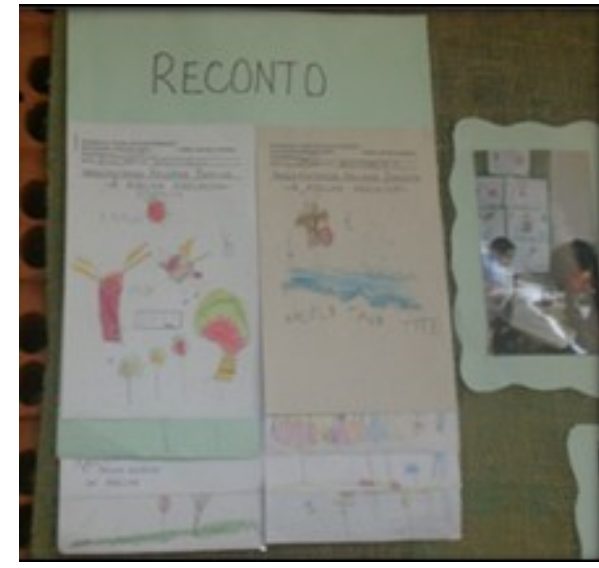

Figura 1b: Produção na SA de expressão e produção.

As atividades desenvolvidas nessa SA são direcionadas a exploração de competência de leitura e escrita, as crianças se envolvem em diversificadas tarefas que estimulam essas competências, como por exemplo, formam palavras a partir de contextos regionais, produzem historinhas, baseadas em lendas da região amazônica, etc. (Figuras la e 1b). Assim, as práticas dessa SA estimulam o hábito de ler, produzir textos, e comunicar ideias, visando, sobretudo a formação de um cidadão, criativo e proativo que possa desenvolver ao máximo competências necessárias para o trabalho individual ou em grupo.

Outra SA que destacamos prioriza à inteligência lógico-matemática. Para Smole (2000, p. 32) as capacidades subentendidas a essa dimensão da inteligência são:

[...] de identificar, formular e resolver problemas, identificar padrões, fazer generalizações, elaborar conjecturas, usar modelos, fatos, contraexemplos e argumentos lógicos para validar ou não uma conjectura e, finalmente, a capacidade de perceber, conceber, analisar e representar objetos geométricos.

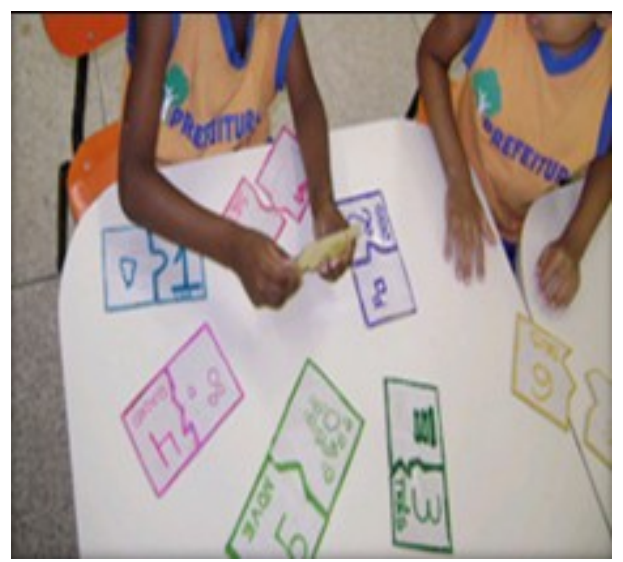

Figura 2 - Sala Ambiente de jogos

Assim a inteligência lógico-matemática está relacionada a capacidade de resolver problemas que podemos relacionar, por exemplo, a identificação de padrões, efetivação de relações entre objetos matemáticos de forma lógica e coerente, uso de argumentações, realização de operações matemáticas num processo investigativo. Dessa forma, os processos utilizados por esta inteligência favorecem procedimentos investigativos, os jogos fazem parte de atividades que exploram essa categoria (MACHADO, 1995; ANTUNES, 1998b) (Figura 2). 
Com o avanço de pesquisas a respeito das Inteligências Múltiplas Gardner acrescentou uma oitava inteligência às categorias originais a chamada Inteligência Naturalista, que inclui a capacidade de discriminar ou classificar diferentes espécies de fauna e flora ou formações naturais como montanhas ou pedras. Nesta categoria podemos explorar situações que possam desenvolver a capacidade de entender e interagir com a natureza, identificar e classificar plantas e animais, compreender a utilidade botânica e curativa das plantas, entender processos naturais, etc. (ARMSTRONG, 1995). As Figuras 3a e 3b ilustram a exploração dessa inteligência na área externa da escola (parquinho) e em uma das SA.

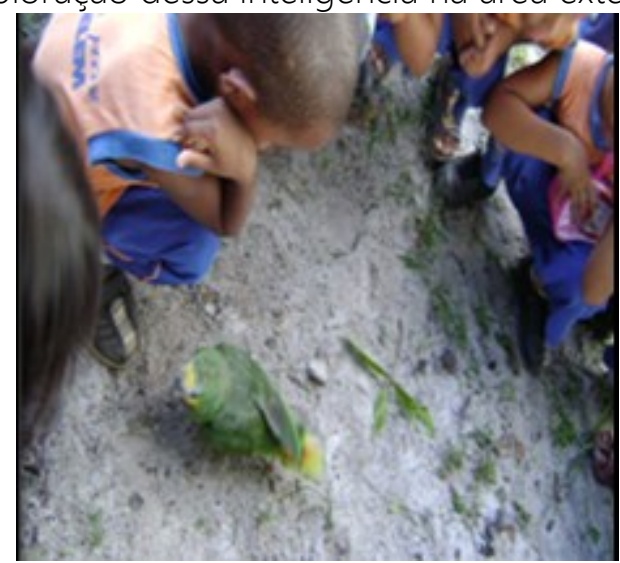

Figura 3a: Ações na SA de Natureza e Sociedade

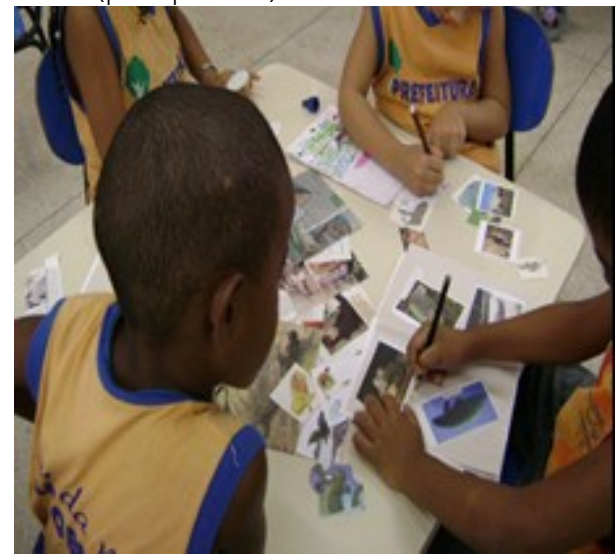

Figura 3a: Ações na SA de Natureza e Sociedade

Outro espaço que podemos destacar são as SA de iniciação musical (Figura 4). Neste ambiente é possível perceber manifestações espontâneas das crianças que interagem e se divertem com a manipulação de instrumentos musicais adaptados. A inteligência musical se manifesta por meio da capacidade de discernimento de sons, sensibilidades para diferenciar ritmose timbres. Cabendo ao professor atuar como um estimulador de talentos ao perceber que a criança manifesta habilidade para apreciar, compor ou reproduzir músicas.

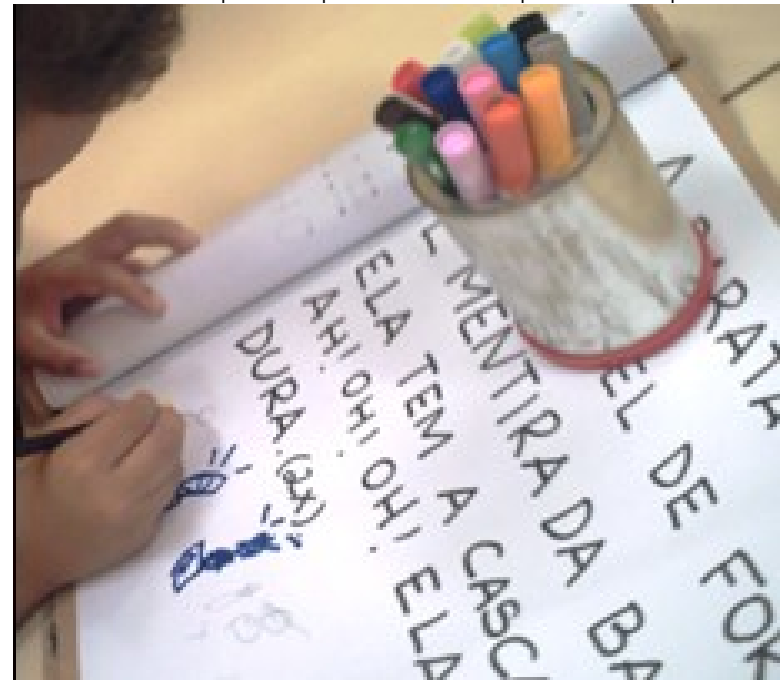

Figura 4: Explorando ritmos e sons na SA de Música

$\mathrm{Na}$ Eco-Escola Alana ainda há mais duas SA onde são desenvolvidas atividades comuns a todos os níveis (Faixa etário 4 e 5 anos), de acordo com os Projetos Pedagógicos. Estas salas necessariamente não se dão em espaço fechado, mas se constituem em espaços livres para realização dasatividades que acontecem na área livre da escola e no espaço da cozinha e refeitório (Quadro 2). 
Quadro 2: Salas Ambientes comuns a todas as turmas

\begin{tabular}{|c|c|c|}
\hline $\begin{array}{c}\text { Sala Ambiente de } \\
\text { Integração/Interação } \\
\text { Área livre coberta } \\
\text { Externa-Parquinho }\end{array}$ & $\begin{array}{l}\text { Inteligência } \\
\text { Pessoal e } \\
\text { Interpessoal }\end{array}$ & $\begin{array}{l}\text { Percepção corporal, autoconhecimento e } \\
\text { relacionamento social, administração das } \\
\text { emoções, ética e empatia - automotivação } \\
\text { e comunicação interpessoal. }\end{array}$ \\
\hline$\frac{\frac{\text { Sala Ambiente de }}{\text { Vivência Alimentar }}}{\text { Copa e cozinha. }}$ & $\begin{array}{c}\text { Todas as } \\
\text { Inteligências }\end{array}$ & $\begin{array}{l}\text { Vocabulário, fluência verbal. Pensamento } \\
\text { lógico, medidas, criatividade, percepção de } \\
\text { sons, peso, media, paladar, descoberta, } \\
\text { interação, reconhecimento de objetos, } \\
\text { comunicação interpessoal. }\end{array}$ \\
\hline
\end{tabular}

Estas áreas livres buscam trabalhar a inteligência espacial de forma a desencadear a estrutura de modelo de mundo no espaço.

O ambiente da SA de Vivência Alimentar está centrado no refeitório da escola dando suporte à Sala Natureza e Sociedade - no desenvolvimento da inteligência naturalista. Suas ações estão pautadas em aspectos voltados para as noções de nutrição saudável, importância de bons hábitos alimentares, postura nos ambientes, valorização das relações interpessoais durante as refeições, os cuidados na preparação e ingestão dos alimentos, a higiene pós-refeições no ambiente com as mãos e com os dentes (Figura 5).

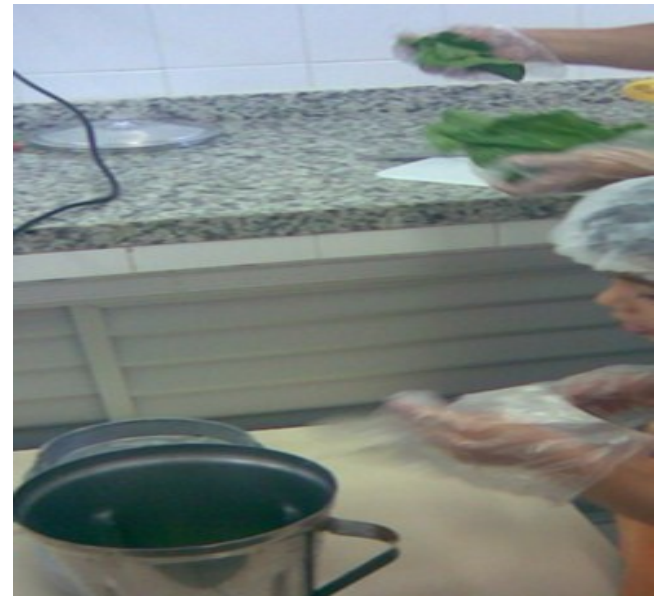

Figura 5: Preparaçãode suco verde servido no lanche

A escola é um espaço que pode pôr em pauta ações necessárias a uma alimentação adequada ao desenvolvimento da criança. Nesse sentido, procuramos estimular hábitos alimentares saudáveis, por meio de atividades educativas que informem e motivam escolhas individuais de alimentação equilibrada evitando a exposição da comunidade escolar a práticas alimentares inadequadas.

\section{Projetos pedagógicos}

Aproveitando a identificação das Turmas por meio das Lendas do Folclore Amazônico todo o desenvolvimento do trabalho é voltado para o letramento, que é efetivado pela organização do currículo escolar em Projetos Didáticos desenvolvidos a partir das lendas. Além dos Projetos Pedagógicos Bimestrais, vários projetos são desenvolvidos, dentre eles:

Projeto Cuidando do Meio Ambiente - Onde a comunidade escolar é incentivada a cuidar do meio onde vive e uma horta escolar existe para o plantio de hortaliças consumidas na escola (Figura 6). 


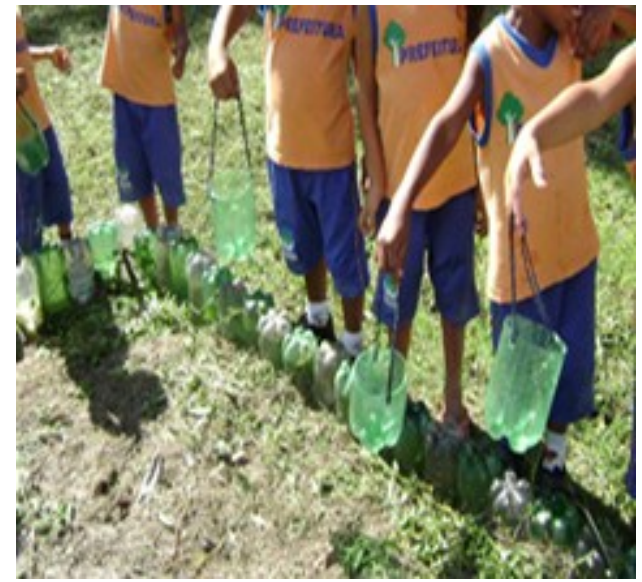

Figura 6: Crianças irrigando a horta

Projeto Teatro, Dança e Música - procura estimular não só as crianças a desenvolver a oralidade, expressividade e relação com o outro, mas envolver os responsáveis, buscando valorizá-los em suas inteligências também. As atividades de integração realizadas às sextas feiras contribuem para que a arte seja vivida constantemente na escola. Os professores tomam a iniciativa, procurando envolver as crianças neste processo (Figura 7).

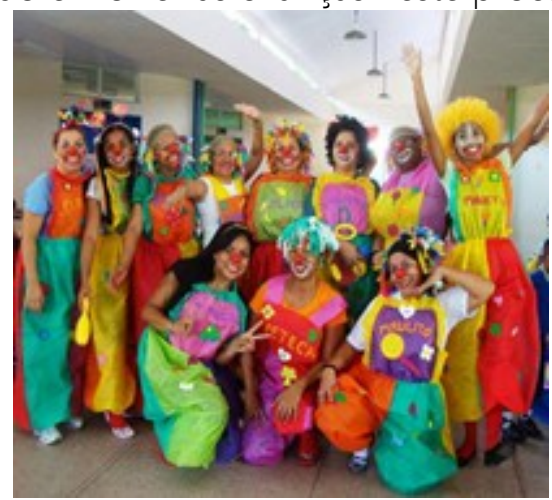

Figura 7: Professoras caracterizadas no dia da criança

Reciclagem é vivida no dia a dia da escola - a Educação Ambiental é um processo permanente no qual os indivíduos e a comunidade tomam consciência do seu Meio Ambiente e adquirem conhecimento, valores, habilidade, experiências e determinação, tornando-se aptos a agir, individual e coletivamente (Figura 8).

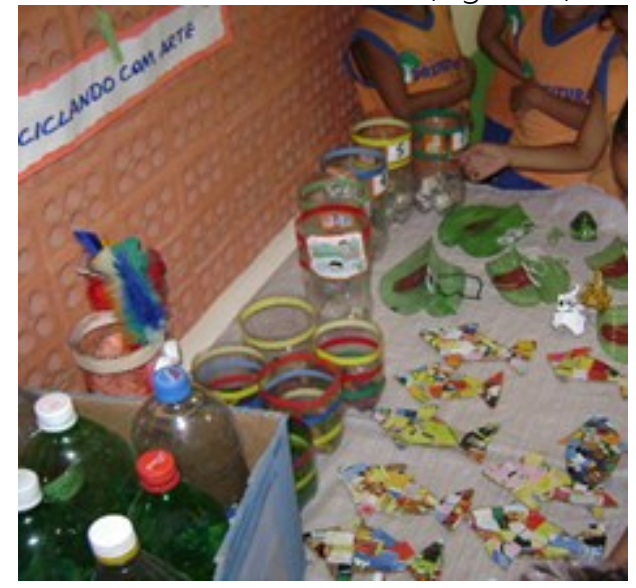

Figura 8: Exposição de trabalhos com reciclagem de materiais 
Neste sentido, na Eco-Escola Alana procura-se estimular as crianças a reaproveitar materiais disponíveis na natureza, fomentando a necessária reflexão acerca da integração do homem com o ambiente, desencadeando assim, valores e atitudes que levam não só a criança, mas a comunidade a transformar qualitativamente o meio em que vive.

\section{Procurando dar atenção individualizada a cada criança}

Não é possível dar atenção a cada criança durante todo o tempo, no entanto, mesmo que não seja possível desenvolver uma atenção individual permanente, é possível manter, mesmo que seja parcialmente ou de tempos em tempos, contatos individuais com cada criança. É o momento da linguagem pessoal, de reconstruir com ela os procedimentos de ação, de orientar o seu trabalho e dar-lhe pistas novas, de apoiá-las na construção de competências necessárias para suas atividades do dia a dia.

A atenção individualizada está na base da cultura da diversidade. É justamente com este estilo de trabalho que atenda individualmente as crianças que as ações na escola realizam as experiências de integração.

Neste sentido também, a Eco-Escola atende crianças com Necessidades Educacionais Especiais, já inseridas no contexto da inclusão social. Estas crianças recebem também apoio especializado da SEMEC.

\section{Processo avaliativo}

Para Sordi (1995), a prática de avaliação é um ato dinâmico co-participativo onde o professor e o aluno assumem os seus papéis, através da implementação do diálogo e da interação respeitosa, comprometendo-se com a construção do conhecimento e a formação de um profissional competente. É um ato essencialmente político, expressando concepções de Homem-Mundo-Educação.

Já Luckesi (1995) entende a avaliação como um juízo de qualidade sobre dados relevantes, tendo em vista uma tomada de decisão.

Hoffmann (1993) vê a avaliação como uma ação provocativa do professor, desafiando o aluno a refletir sobre as experiências vividas, a formular e reformular hipóteses, direcionando para um saber enriquecido.

A avaliação é uma constante em nosso dia a dia. Não somente aquela que fazemos ou que estamos comprometidos a fazer quando nos encontramos na Escola, mas também, aquele em que avaliamos impressões e sentimentos. É assim que, nas interações cotidianas, em casa, em nossa trajetória profissional, durante o lazer, a avaliação sempre se faz presente e inclui um julgamento de valor sobre nós mesmos, sobre o que estamos fazendo, sobre o resultado de trabalho.

Na proposta da Eco-Escola Alana a avaliação é entendida enquanto ato pedagógico impulsionador da aprendizagem. Tem como objetivo diagnosticar a situação em que se encontra o aluno em termos de dificuldades, facilidades e possibilidades de forma a permitir a minimização ou eliminação das mesmas, a correção das falhas e o estímulo para que continue progredindo. Não se avalia para classificar, não para apontar, mas se avalia para incluir.

Com relação aos alunos todos são inclusos. Os professores selecionam 4 atividades bimestrais realizadas pelas crianças e entregam na Coordenação para a construção do Portfólio de cada uma delas. Estas atividades contêm registros feitos pelas crianças (desenhos, escrita livre) que serão analisadas para observação do progresso das mesmas em relação a apropriação do conhecimento. 
Também a Coordenação Pedagógica juntamente com o corpo discente estudou a Teoria das Inteligências Múltiplas e assim foi construído um quadro de observação do aluno de acordo com o trabalho realizado nas Salas Ambientes e sua linha de estimulação. A partir deste quadro o professor elabora um pequeno texto sobre o desenvolvimento do aluno naquele bimestre. As observações do professor são repassadas aos pais em reunião do Conselho de Ciclo que é realizada ao final de cada semestre.

Não só as crianças são avaliadas, mas se avalia todo o processo:

As avaliações são efetivadas em reuniões de ciclo onde os responsáveis pelos alunos avaliam o desenvolvimento da proposta, o trabalho realizado pela direção, coordenação, professores, limpeza da escola, merenda oferecida e também se auto avaliam, pois, avaliar é fornecer informações úteis que possam contribuir para melhoria do que vem sendo realizado. Este processo de avaliação é realizado duas vezes ao ano.

Semestralmente os profissionais que atuam na escola também avaliam e se auto avaliam. Ou seja, avaliar-se a si mesmo (a) serve inclusive para re-significar a postura frente às ações realizadas na Eco-Escola, o comprometimento pessoal com a formação continuada, o envolvimento nos trabalhos, e por fim influenciará até mesmo no modo de ver a criança.

\section{Considerações finais}

O objetivo deste artigo foi refletir sobre a dinâmica de funcionamento das Salas Ambientes de uma Eco-Escola localizada na periferia de Belém do Pará, tendo a Teoria das Inteligências Múltiplas como mola propulsora de um fazer pedagógico diferenciado. Evidenciamos que é possível a partir de um planejamento coletivo integrar teoria e prática.

A proposta aqui analisada se tornou possível a partir do envolvimento de pessoas que acreditaram ser possível implantar uma proposta diferenciada e tão difundida em pesquisas que refletem sobre a melhoria do processo de ensino e aprendizagem, nas ações desenvolvidas nas SA observarmos as crianças engajadas na aprendizagem por meio do rodízio entre as salas ambientes.

Neste rodízio as particularidades afloram e os discentes descobrem o gosto pelo aprender, as inteligências só entendem os argumentos do desejo: elas são ferramentas e brinquedos dos desejos. Na Eco-Escola isso acontece, as ações desonvolvidas levam as crianças a alcançarem novos níveis de raciocínio que as ajudarão a participar do processo de construção do saber. 


\section{Referências}

ANDRÉ, M. E.; DALMASO, A. Etnografia da prática escolar. 12ª ed. Campinas-SP: Papirus, 2005.

ANTUNES, C. Como desenvolver conteúdos explorando as inteligências múltiplas. Petrópolis: Vozes, 2001.

ANTUNES, C. Inteligências Múltiplas e seus estímulos. Campinas. Papirus, 1998a.

ANTUNES, C. Jogos para estimulação das múltiplas inteligências. Petrópolis: Vozes, 1998b.

ARMSTRONG, T. Inteligências Múltiplas na sala de aula. $2^{a}$ ed., Trad. Maria Adriana VeríssimoVeronese. Porto Alegre: Artes Médicas, 1995.

BRASIL. Lei de Diretrizes e Bases da Educação (LDB). Lei Federal nº 9.394 de 26/12/1996.

CAMPOS, S. P. P.; SANTOS, M. G. S. P. A leitura e a teoria das inteligências múltiplas: um encontro possível em sala de aula. Norte Científico, v. 4, n. 1, 2009.

DEMO, P. Educação e Qualidade. São Paulo: Editora Papirus, 1992.

ELIAS, M. D. C. Pedagogia Freinet - Teoria e prática. São Paulo: Papirus, 2000. (livro Conscientização: teoria e prática da libertação. São Paulo: Cortez e Moraes, 1975).

GARDNER, H. Inteligências Múltiplas: a teoria na prática. Porto Alegre: Artes Médicas, 1994.

GOLEMAN, D. Inteligência Emocional. Rio de Janeiro: Objetiva, 1995.

HOFFMANN, J. M. L. Avaliação: mito e desafio-uma perspectiva construtivista. Educação e Realidade, Porto Alegre, 1993.

LUCKESI, C. C. Avaliação da aprendizagem escolar. São Paulo: Cortez, 1995.

MACHADO, N. J. Epistemologia e Didática: as concepções de conhecimento e inteligência e a prática docente. São Paulo: Cortez, 1995.

SMOLE, K. C. S. A matemática na Educação Infantil: a teoria das inteligências múltiplas na prática escolar. Porto Alegre: Artmed, 2000.

SMOLE, K. C. S. Múltiplas Inteligências na Prática Escolar. Brasília: Ministério da Educação, Secretaria de Educação a Distância, 1999 - Cadernos da TV Escola. Inteligências Múltiplas, ISSN 1517-2341 n.1.

SORDI, M. R. A prática de avaliação do ensino superior: uma experiência na enfermagem. São Paulo: Cortez/PUCCAMP, 1995.

VYGOSTSKY.L. S. Pensamento e linguagem. São Paulo. Martins Fontes, 1991. 